\title{
EDUCAÇÃO ANTIDENGUE: UM RELATO DE EXPERIÊNCIA
}

\author{
Marise Maleck \\ Universidade Severino Sombra \\ marise.maleck@gmail.com \\ Igor Luiz Souza da Cruz \\ Universidade Severino Sombra \\ igorlscruz@gmail.com \\ Michele Teixeira Serdeiro \\ Universidade Severino Sombra \\ mserdeiro@gmail.com
}

Bárbara Mendes Pardal Universidade Severino Sombra barbara.m.pardal@gmail.com

\author{
Renata Fraga Pinheiro \\ Universidade Severino Sombra \\ rfpinheiro@ufrrj.br \\ Simone Pereira Alves \\ Universidade Severino Sombra \\ enomisalves@hotmail.com
}

\begin{abstract}
Resumo
Aedes aegypti (L., 1762) é o principal vetor reconhecido como transmissor do vírus da dengue. Este vetor, uma vez adaptado aos hábitos humanos, não encontra dificuldades para se reproduzir em ambientes domésticos que disponham de recipientes acumuladores de água, encontrados facilmente nas ruas e nos lixos das cidades. As instituições de ensino têm papel fundamental na formação de jovens como cidadãos disseminadores de práticas a favor da promoção da saúde. Com a finalidade de promover a educação para o controle do mosquito vetor do vírus dengue, este trabalho foi desenvolvido através de atividades lúdicas e didáticas nas escolas públicas e particulares do Centro-Sul Fluminense, cidades, centros culturais e espaços públicos do Estado do Rio de Janeiro. Os resultados apontaram respostas positivas acima de $80 \%$ sobre o tema Aedes-dengue-controle. O projeto atendeu a 2500 participantes. O Projeto Educação Antidengue demonstrou que a educação é uma ferramenta eficaz no tripé educação-saúde-meio ambiente.
\end{abstract}

Palavras chave: Aedes Aegypti. Educação e Saúde. Dengue. Educação e Ambiente.

\begin{abstract}
Aedes aegypti (L., 1762) is the main vector recognized as a dengue virus transmitter. This vector, once adapted to human habits, finds it easy to reproduce in homes that have open water containers, easily found in city streets and garbage dumps. Educational institutions play a fundamental role in the formation of young people as disseminator citizens in favor of health improvement practices. In order to promote education for the control of the dengue virus mosquito vector, this work was developed through recreational and educational activities in Central-South Rio de Janeiro state public and private schools, cities, cultural centers and public spaces. The results showed positive responses above $80 \%$ of the Aedes-denguecontrol issue. The project had 2500 participants. The Antidengue Education Project demonstrated that education is an effective tool regarding education, health and the environment.
\end{abstract}

ANTI DENGUE EDUCATION: A EXPERIENCE REPORT

Keywords: Aedes Aegypti. Education and Health. Dengue. Education and Environment.

\section{EDUCACIÓN ANTIDENGUE: UN RELATO DE EXPERIENCIA}

Resumen

Aedes aegypti (L., 1762) es el principal vector reconocido como transmisor del virus del dengue. Este vector, una vez adaptado a los hábitos humanos, no encuentra dificultades para reproducirse en ambientes domésticos que dispongan de recipientes acumuladores de agua, encontrados fácilmente en las calles y basureros de las ciudades. Instituciones educacionales tienen el papel fundamental en la formación de jóvenes como ciudadanos diseminadores de prácticas a favor de la promoción de la salud. Con la finalidad de promover la educación para el control del mosquito vector del virus del dengue, se llevó a cabo este trabajo mediante actividades lúdicas y didácticas en escuelas públicas y particulares del CentroSur Fluminense, ciudades, centros culturales y espacios públicos del Estado de Río de Janeiro. Los resultados revelaron respuestas positivas por encima de 80\% acerca del tema Aedes-dengue-controle. El Proyecto Educación Antidengue demostró que la educación constituye una herramienta eficaz en la tríada educación-salud-medio ambiente.

Palabras clave: Aedes Aegypti. Educación y Salud. Dengue. Educación y Ambiente. 
Educação antidengue: um relato de experiência

\section{INTRODUÇÃO}

A dengue é objeto da maior campanha de saúde pública do Brasil que se concentra no controle do Aedes aegypti (Linnaeus, 1762), único vetor reconhecido como transmissor do vírus da dengue em nosso país. Este mosquito, uma vez adaptado aos hábitos humanos, não encontra dificuldades para se reproduzir em ambientes domésticos que disponham de recipientes que acumulem água, encontrados facilmente nas ruas e nos lixos das cidades (TAUIL, 2001). Para que o controle da dengue seja efetivo, discussões recentes apontam para a necessidade de maiores investimentos em metodologias adequadas, a fim de sensibilizar a população sobre a necessidade de mudanças de comportamento que objetivem o controle do vetor; e no manejo ambiental, incluindo a ampliação do foco das ações de controle racional de vetores, para minimizar a utilização de inseticidas e, dessa forma, garantir maior sustentabilidade às ações (BRAGA e VALLE, 2007). Um dos pontos chave do controle de vetores é o papel das comunidades na eliminação dos criadouros, tarefa difícil de obter êxito, devido à quantidade e aos diferentes tipos de criadouros (BRASSOLATI e ANDRADE, 2002; FRANÇA et al., 2002).

Diante desta premissa, a comunicação, a educação e mobilização social são ações fundamentais para o bom desempenho dos programas de prevenção e promoção da saúde, principalmente pela sua capacidade de abrir espaços de diálogo e conversação entre profissionais,

agentes de saúde e população, na busca de solução para os problemas que os afetam. É muito importante relativizar o poder dessas práticas em produzir ou induzir mudanças de comportamentos e atitudes, especialmente em contextos tão adversos à proteção e promoção da saúde (RANGEL, 2008).

Essas ferramentas são capazes de transformar e induzir novos comportamentos, e demonstram serem mais eficazes quando em crianças e adolescentes. Neste contexto, as instituições de ensino têm papel fundamental na formação de jovens como cidadãos disseminadores de práticas a favor da promoção em saúde tornando-os agentes sociais importantes em suas comunidades. Esta proposta corrobora com projetos interdisciplinares, como a citação de FREIRE (1996) "tanto educadores quanto educandos envoltos numa pesquisa, não serão mais os mesmos. Os resultados devem implicar em mais qualidade de vida, devem ser indicativos de mais cidadania, de mais participação nas decisões da vida cotidiana e da vida social".

Pela sua representatividade, a escola é um espaço privilegiado para a base do envolvimento da população no controle de vetores de doenças endêmicas e parasitárias (REGIS et al., 1995) e precisam ser abordadas de maneira consistente, criativa, e adequada às realidades 
Educação antidengue: um relato de experiência

locais (LENZI e COURA, 2004). Essa abordagem pode ser realizada através das atividades lúdicas associadas a ações educativas, já que o lúdico possui características tais como: estímulo da imaginação, construção da personalidade, exploração e manipulação de objetos que não fazem parte do cotidiano da criança, e também proporciona o contato com outras pessoas (KISHIMOTO, 1994). A escola normalmente envolve membros da maioria das famílias do bairro, e a dengue e o controle do mosquito são temas excelentes para diferentes tipos de abordagem; pela sua incorporação ao conteúdo programático e sua reprodução nos anos subsequentes; pela oportunidade de aproximação de um problema existente na comunidade e, principalmente, por necessitar de mudanças de atitudes. York (1993) indica que, de fato, a mudança de hábitos é muito mais fácil de ser conseguida entre as crianças do que nos adultos, uma vez que as mesmas são muito mais estimuladas pela própria curiosidade.

O projeto educação antidengue teve como objetivo mobilizar e sensibilizar a comunidade escolar e a população em geral no estado do Rio de Janeiro, quanto à importância de um estado de vigilância para $A$ e. aegypti, com a proposta de divulgar o conhecimento científico, através de atividades lúdicas e ações educativas, de modo a buscar parceiros no processo de prevenção da dengue.

\section{MATERIAIS E MÉTODOS}

\section{Local de estudo}

A execução do projeto constou de visitas a nove escolas no município de Vassouras, RJ, sendo quatro estaduais, três municipais, um centro integrado de educação pública e uma escola particular, perfazendo um total de 712 alunos participantes. Os eventos de extensão foram realizados em locais públicos, nos municípios fluminenses de Miguel Pereira, Três Rios; Maricá; em Centros Culturais; locais públicos no município de Vassouras; e no campus Universitário da Universidade Severino Sombra/USS, no município de Vassouras.

\section{Ações educativas}

As atividades foram realizadas pela equipe do Laboratório de Insetos Vetores da Universidade Severino Sombra/USS, composta de estudantes de doutorado/FIOCRUZ, mestrado/USS, iniciação científica (PIBIC-USS; PIBIC-FAPERJ; PIBIC-CNPq), jovens 
Educação antidengue: um relato de experiência

talentos/FAPERJ e pelo professor coordenador, no período de 2011-2014 e constaram de visitas às escolas públicas e particulares, com agendamento prévio de acordo com o projeto pedagógico de cada escola, e eventos públicos. As atividades realizadas nas escolas constaram de oficinas, palestras, jogos, teatro, música e foram distribuídas de acordo com a escolaridade em $1^{\circ}$ e $2^{\circ}$ segmentos do Ensino Fundamental, com duração prevista entre 3-4 horas.

As ações no primeiro segmento constaram da peça teatral "O Mosquito Dengoso", com informações sobre a importância do representante da Secretaria de Vigilância Sanitária, responsável pela visita domiciliar, os possíveis focos do mosquito, os depósitos de água acumulada e os cuidados necessários no controle do culicídeo, como visto no trecho da história em quadrinhos homônima (MALECK et al., 2012). Conforme a mitologia grega, "Pandora" ganhou uma caixa em que guardava todo o mal do mundo, mas também a esperança (POUZADOUX et al., 2001). Sendo assim, se utilizou a Caixa de Pandora que, na dinâmica da brincadeira, os objetos que pudessem servir de criadouro do mosquito, representavam o "mal", e os demais representavam a esperança. Os objetos do "bem", quando retirados da Pandora, foram doados aos alunos.

As demais atividades, como corrida maluca, com um ponto de partida e de chegada; lupa mágica e labirinto, todas tiveram o propósito de fornecer informações sobre os potenciais criadouros de Ae. aegypti.

Como atividade de expressão livre, máscaras pré-confeccionadas com o formato da probóscide do mosquito foram oferecidas para colorir.

A história em quadrinhos "O mosquito dengoso" (MALECK et al., 2012), o livro de atividades (MALECK et al., 2015) e o CD de música homônima (SILVA e MALECK, 2012) foram distribuídos aos participantes.

No segundo segmento, e de acordo com a escolaridade, o tema foi desenvolvido com palestras e oficinas, abordando o aspecto morfobiológico e o ciclo de vida do mosquito (MINISTÉRIO DA SAÚDE, 2001). A avaliação desta atividade foi a confecção, pelos estudantes, de cartazes informativos sobre o assunto abordado. A gravidade da doença, o mecanismo de transmissão e a prevenção ao vetor também foram focos de discussão. As oficinas constaram de aulas experimentais com os ovos, as larvas, as pupas e os adultos de Ae. aegypti e $A$ e. albopictus (in vivo).

O método avaliativo do aprendizado para ambos os segmentos foi realizado através do formulário "sim ou não do Dr. Mosquitão" (Figura 1) e aplicados aos estudantes, em amostragem aleatória, pelo professor regente das turmas. 

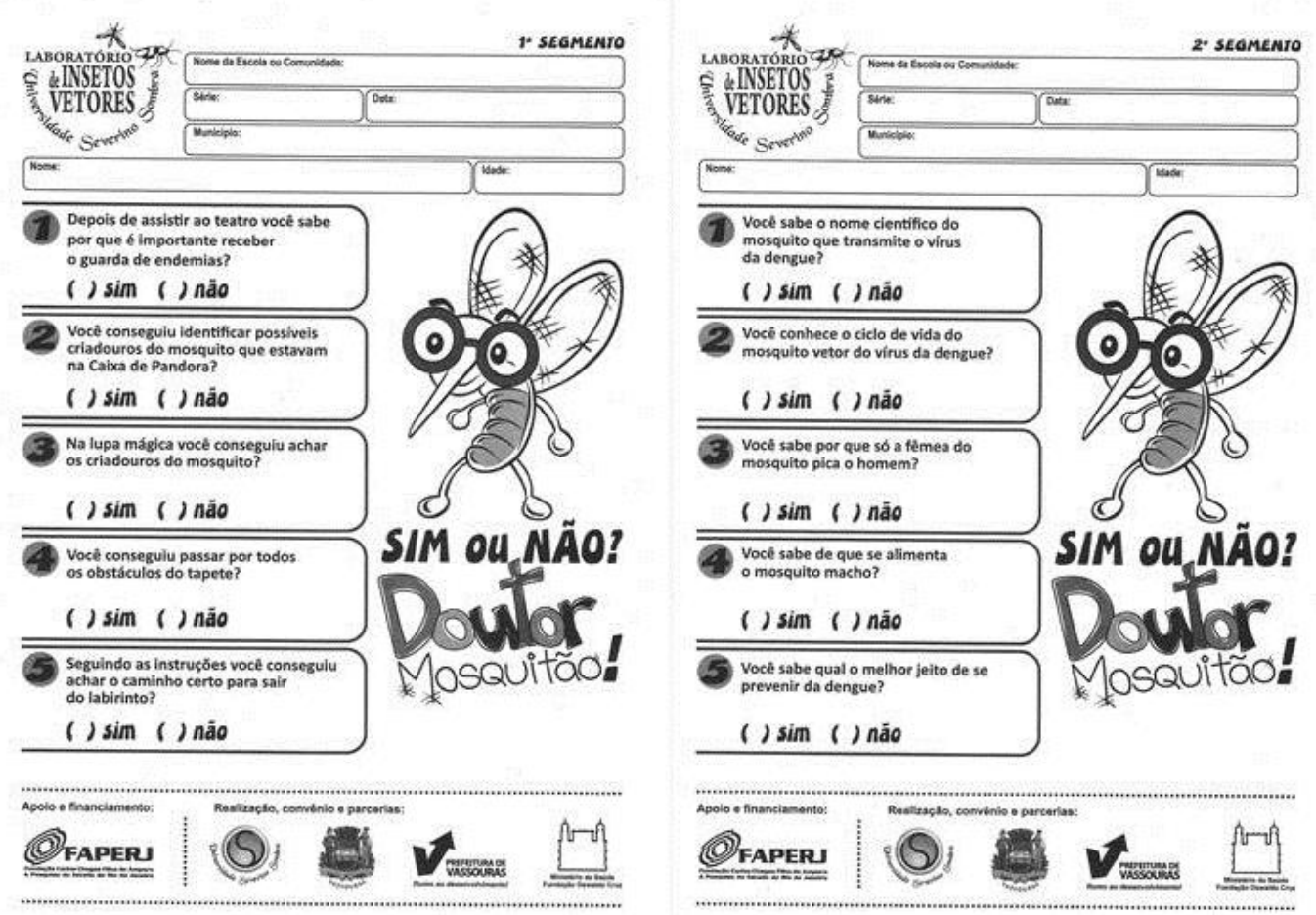

Figura 1: Formulário utilizado para avaliação do aprendizado: “Sim ou Não? Dr. Mosquitão!”

Este estudo, licença 001/2010/CEP-USS, de pesquisa e extensão, está diretamente ligado ao incentivo e popularização da ciência, e na formação de estudantes, como agentes e promotores efetivos de ações, no âmbito educação-ambiente-saúde.

Os resultados dos formulários de avaliação “Sim ou Não? Dr. Mosquitão!” foram mensurados por somatório e percentual.

\section{RESULTADOS E ANÁLISES}

A proposta de "educar com diversão" forneceu subsídios importantes para o conhecimento sobre o mosquito vetor da dengue, e induziu mudanças de comportamento no que tange o ambiente e saúde.

As atividades contaram com 2500 pessoas no total, sendo estes estudantes, professores e o público em geral dos municípios de Vassouras, Três Rios, Maricá e Miguel Pereira (Tabela 1). 
Educação antidengue: um relato de experiência

Tabela 1: Resultado das ações educativas, locais da realização e número de participantes.

\begin{tabular}{lccc}
\hline Atividades & Número de atividades & Local das atividades & $\begin{array}{c}\text { Número de } \\
\text { participantes }\end{array}$ \\
\hline \multirow{2}{*}{ Escolas } & 8 & Vassouras & 694 \\
Subtotal & 1 & Vassouras & 18 \\
& & & 712 \\
\hline \multirow{2}{*}{ Eventos } & 4 & Vassouras & 409 \\
& 4 & Vassouras & 725 \\
& 1 & Vassouras & 366 \\
Subtotal & 1 & Três Rios & 108 \\
TOTAL & 1 & Maricá & 74 \\
& & Miguel Pereira & 106 \\
\hline
\end{tabular}

As atividades realizadas com os estudantes do primeiro segmento do ensino fundamental resultaram em 552 respostas e demonstraram principalmente a importância do guarda de endemias no controle do mosquito. A caixa de pandora, o labirinto e a peça teatral foram as ações mais atrativas, representando acima de 80\% de aceitação pelos estudantes (Tabela 2).

Tabela 2: Respostas positivas relacionadas às atividades (peça teatral, caixa de pandora, lupa mágica, corrida maluca e labirinto) realizadas com 137 alunos do $1^{\circ}$ segmento do ensino fundamental, em 4 escolas do município de Vassouras, RJ.

\begin{tabular}{cccccc}
\hline Escolas & $\begin{array}{c}\text { Peça } \\
\text { teatral }\end{array}$ & $\begin{array}{c}\text { Caixa de } \\
\text { pandora }\end{array}$ & $\begin{array}{c}\text { Lupa } \\
\text { mágica }\end{array}$ & $\begin{array}{c}\text { Corrida } \\
\text { maluca }\end{array}$ & Labirinto \\
\hline A & 11 & 16 & 6 & 10 & 9 \\
B & 38 & 37 & 32 & 23 & 33 \\
C & 32 & 43 & 42 & 30 & 39 \\
D & 30 & 29 & 25 & 33 & 34 \\
Total (RP) & 111 & 125 & 105 & 96 & 115 \\
\% & 81 & 91 & 77 & 70 & 84 \\
\hline
\end{tabular}

Legendas: $\mathrm{RP}=$ Respostas positivas. 
Educação antidengue: um relato de experiência

As atividades realizadas com o segundo segmento do Ensino Fundamental, com a participação de 222 estudantes, o nome científico e os métodos de controle de Ae. aegypti foram os assuntos mais conhecidos, em torno de $84 \%$ em comparação ao ciclo de vida, hábitos e tipo de alimentação (26-36\%) (Tabela 3A). Após as atividades, os resultados (Tabela 3B), demonstraram um aumento significativo do conhecimento sobre o inseto vetor $(95 \%)$ e os métodos de controle (98\%). Os assuntos abordados como o ciclo de vida atingiram 86\% de respostas corretas, enquanto os hábitos e a alimentação dos insetos apresentaram um resultado de 70-75\% (Tabela 3B).

Tabela 3: Respostas positivas da avaliação prévia (3A) e posterior (3B) às atividades realizadas com 222 estudantes do $2^{\circ}$ segmento do ensino fundamental, em 9 escolas do município de Vassouras, RJ.

\begin{tabular}{|c|c|c|c|c|c|}
\hline Escolas & $\begin{array}{c}\text { Nome } \\
\text { científico }\end{array}$ & $\begin{array}{l}\text { Ciclo de } \\
\text { vida }\end{array}$ & Hábitos & Alimentação & $\begin{array}{c}\text { Prevenção e } \\
\text { controle }\end{array}$ \\
\hline \multicolumn{6}{|l|}{$\mathbf{A}$} \\
\hline $\mathrm{A}$ & 17 & 4 & 4 & 5 & 23 \\
\hline $\mathrm{B}$ & 19 & 7 & 5 & 4 & 17 \\
\hline C & 61 & 44 & 31 & 28 & 62 \\
\hline $\mathrm{D}$ & 63 & 9 & 13 & 8 & 66 \\
\hline $\mathrm{E}$ & 17 & 11 & 2 & 7 & 18 \\
\hline $\mathrm{F}$ & 10 & 5 & 4 & 8 & 3 \\
\hline Total (RP) & 187 & 80 & 59 & 60 & 189 \\
\hline$\%$ & 84 & 36 & 26 & 27 & 85 \\
\hline \multicolumn{6}{|l|}{ B } \\
\hline $\mathrm{A}$ & 30 & 28 & 24 & 26 & 34 \\
\hline $\mathrm{B}$ & 20 & 18 & 19 & 19 & 20 \\
\hline C & 64 & 57 & 37 & 36 & 67 \\
\hline $\mathrm{D}$ & 69 & 61 & 56 & 57 & 68 \\
\hline $\mathrm{E}$ & 18 & 18 & 12 & 18 & 19 \\
\hline $\mathrm{F}$ & 10 & 9 & 7 & 10 & 10 \\
\hline Total (RP) & 211 & 191 & 155 & 166 & 218 \\
\hline$\%$ & 95 & 86 & 70 & 75 & 98 \\
\hline
\end{tabular}

Legendas: $\mathrm{RP}=$ Respostas positivas. 
Educação antidengue: um relato de experiência

O resultado do concurso de cartazes realizado como material didático de fixação do aprendizado, foi divulgado em evento científico no Centro Cultural (CeCult) da Universidade Severino Sombra, e os resumos e textos publicados on-line no site institucional, conforme link: http://www.uss.br/arquivos/Escola dengue redacoes selecionadas.pdf.

De acordo com LENZI e COURA (2004) uma maior aproximação do campo científico ao senso comum se faz necessária para a interação entre essas formas de conhecimento, permitindo a construção de mensagens mais direcionadas e, possivelmente, de maior contribuição ao esclarecimento da população. Paulo Freire (1996) afirma que "ensinar não é transferir conhecimento, mas criar as possibilidades para a sua própria produção ou a sua construção". De acordo com Huizinga (1971) e Piaget (1970), a atividade lúdica supõe uma ordenação da realidade, seja ela subjetiva ou intuitiva, ou objetiva e consciente. Para Piaget (1978) a atividade lúdica humana contribui para o desenvolvimento porque propicia a descentração do indivíduo, a aquisição de regras, a expressão do imaginário e a apropriação do conhecimento.

Educação em saúde é um passo essencial no programa de controle de vetores, uma vez que demonstra a eficiência da informação e conhecimento científico do vetor e da transmissão de doenças para a população. O conhecimento sobre o ciclo de vida do vetor, sua ecologia e biologia devem ser disseminados a fim de promover condições saudáveis e auxiliar na erradicação dos criadouros dos mosquitos (AZIS et al., 2014).

Os resultados desta proposta possibilitaram novos espaços de diálogos e conversação e, através das atividades realizadas, sanaram dúvidas da população e introduziram conhecimento científico às comunidades, transformando teoria em ações concretas envolvendo educação, sociedade e pesquisa.

\section{CONSIDERAÇÕES FINAIS}

Este estudo mostrou que a educação realizada de forma lúdica e com uma linguagem adequada é uma forma propícia de educar para a saúde e o ambiente, e formar novos multiplicadores do conhecimento no controle do mosquito e prevenção da dengue, febre amarela urbana, zika e chikungunya no município. 
Educação antidengue: um relato de experiência

\section{AGRADECIMENTOS}

Os autores agradecem o apoio financeiro à Fundação Carlos Chagas Filho de Amparo à Pesquisa do Estado do Rio de Janeiro (FAPERJ). Projeto vinculado ao PROCESSO n. E26/111.481/2010, Difusão e popularização da Ciência e Tecnologia do Rio de Janeiro; às escolas participantes; Pró-Reitoria de Pesquisa e Pós-graduação/USS; Pró-Reitoria de Extensão/USS; as bolsas PIBIC e PIBITI/USS; as bolsas PIBIC/FAPERJ e PIBIC/CNPq; as bolsas de JOVENS TALENTOS/FAPERJ; e ao Convênio firmado com a Secretaria de Saúde do Município de Vassouras, Vassouras, RJ. Os autores agradecem, em especial, a João Luiz da Silva, pela letra e música do "Mosquito dengoso"; a Taíssa Maleck e a Diego Luiz Souza da Cruz pelas artes gráficas, e ao Prof. Adiel Queiroz Ricci, pela revisão do manuscrito.

\section{REFERÊNCIAS}

AZIZ, A.T.; AL-SHAMI, S.A.; MAHYOUB, J.A.; HATABBI, M.; AHMAD, A.H.; RAWI, C.S. Promoting health education and public awareness about dengue and its mosquito vector in Saudi Arabia. Parasites \& Vectors, v. 7, p. 487, 2014.

BRAGA, I.A.; VALLE, D. Aedes aegypti: histórico do controle no Brasil. Epidemiologia e Serviços de Saúde, Brasília, v. 16, n. 2, p.113-118, 2007.

Brasil. Ministério da Saúde. Fundação Nacional de Saúde (FUNASA). Oficinas de Educação em Saúde e Comunicação. Vamos fazer juntos. Brasília-DF, 2001.

BRASSOLATTI, R.C.; ANDRADE, C.F.S. Avaliação de uma intervenção educativa na prevenção da dengue. Ciência \& Saúde Coletiva, v. 7, n. 2, p. 243-245, 2002.

FRANÇA, E.; DE PAULA, J.C.; SILVA, R.R.; ANUNCIAÇÃO, L.R. Participação da população em projeto de controle de dengue em Belo Horizonte, Minas Gerais: uma avaliação. Informe Epidemiológico do SUS, v. 11, n. 4, p. 205-213, 2002.

FREIRE, P. Pedagogia da Autonomia: Saberes Necessários à Prática Educativa. São Paulo: Paz e Terra, 1996.

HUIZINGA, J. Homo ludens - O jogo como elemento da cultura. São Paulo, Universidade de São Paulo e Perspectiva, p. 3, 1971.

KISHIMOTO, T.M. O jogo e a educação infantil. São Paulo: Ed. Pioneira, 1994.

LENZI, M.F.; COURA, L.C. Prevenção de dengue: a informação em foco. Revista da Sociedade Brasileira de Medicina Tropical, v. 37, n. 4, p. 343-350, 2004. 
Educação antidengue: um relato de experiência

MALECK, M.; ALVES, S.P.; CRUZ, I.S.; PARDAL, B.M.; PINHEIRO, R.F. O mosquito Dengoso. $1^{\circ}$ edição. Vassouras. Universidade Severino Sombra, 2012.

MALECK, M.; CRUZ, D.L.S.; PARDAL, B.M.; CRUZ, I.L.S.; SERDEIRO, M.T.; ALVES, S.P. Livro de atividades- $\mathbf{O}$ mosquito dengoso. $1^{\mathrm{a}}$ edição. Vassouras. Universidade Severino Sombra, 16p, 2015.

PIAGET, J. A Formação do Símbolo na Criança. Rio de Janeiro: Ed. Zahar, 1978.

PIAGET, J. Psicologia e pedagogia. Trad. Dirceu Accioly Lindoso e Rosa Maria Ribeiro da Silva. Rio de Janeiro / São Paulo: Forense (Ed. Original: 1969), 1970.

POUZADOUX, C.; MANSOT, F.; BRANDÃO, E. Contos e lendas da mitologia grega. São Paulo: Companhia das Letras, 2001.

RANGEL-S, M.L. Dengue: educação, comunicação e mobilização na perspectiva do controle - propostas inovadoras. Interface (Botucatu), v. 12, n. 25, p. 433-441, 2008.

REGIS, L.; SILVA-FILHA，M.H.N.L.; OLIVEIRA， C.M.F.; RIOS， E.M.; SILVA， S.B.; FURTADO, A.F. Integrated control measures against Culex quinquefasciatus, the vector of filariasis in Recife. Memórias do Instituto Oswaldo Cruz, v. 90, n. 1, p. 115-119, 1995.

SILVA, J.L.; MALECK, M. Cd O mosquito dengoso. Laboratório de Insetos Vetores. Universidade Severino Sombra, Vassouras, RJ, 2012.

TAUIL, P.L. Urbanização e ecologia do dengue. Cadernos de Saúde Pública, Rio de Janeiro, v. 17(supl.), p. 99-102, 2001.

YORK, A.C. An Educational Assist to Urban Pest Management Purdue University, West Lafayette, Indiana, USA: Proceeding of the 187 International Conferences on Insect Post in the Urban Environment/ Wildey, K.J. E.W.H. Robinson eds., 1993. 